\title{
La Ley de Enjuiciamiento Criminal y la Ley 4/2015 del Estatuto de la Víctima de delito: sus lagunas y consecuencias en el ámbito de la traducción y la interpretación
}

\author{
María Fernández de Casadevante Mayordomo ${ }^{1}$
}

Recibido: 4 de marzo 2020 / Aceptado: 20 de agosto 2020

Resumen. No se puede negar que el fenómeno migratorio se ha visto intensificado y, como consecuencia, muchos inmigrantes que desconocen nuestra lengua necesitan ser asistidos judicialmente. A nivel nacional son varios los instrumentos y leyes que de una u otra forma recogen el derecho a la traducción y a un intérprete en el entorno legal, teniendo en cuenta que el inmigrante puede necesitar la presencia de un intérprete como acusado, pero también como víctima. No obstante, nos encontramos con que la Ley de Enjuiciamiento Criminal y la Ley 4/2015 del Estatuto de la Víctima de delito cuentan en su articulado con elementos que no garantizan la igualdad de condiciones en las relaciones con la justicia de aquellas personas que no comparten el idioma del tribunal, y permiten que cualquiera lleve a cabo dicha labor de traducción e interpretación.

Palabras clave: Ley de Enjuiciamiento Criminal, Estatuto de la Víctima, traducción e interpretación, transposición, igualdad de condiciones.

\section{[en] The Spanish Criminal Procedure Act and the Spanish Law 4/2015 on the standing of victims of crime: gaps and consequences in translation and interpreting}

\begin{abstract}
As a result of increasing migration, many immigrants with no knowledge of our language require legal assistance. At the national level, there are several instruments and laws that include, to a certain degree, the right to translation and interpretation in the legal field, and which take into account that the immigrant may need the presence of an interpreter both when acting as a defendant and as a victim. However, we find that the Spanish Criminal Procedure Act and Spanish Act 4/2015, on the Standing of Victims of Crime, contain aspects that do not guarantee equal conditions regarding access to justice for those not sharing the language of the court.
\end{abstract}

Key Words: Spanish Criminal Procedure Act. Spanish Act 4/2015, translation and interpretation, transposition, equal conditions.

Sumario. Introducción. 2. Ley de Enjuiciamiento Criminal. 3. Ley 4/2015 del Estatuto de la Víctima de Delito. 4. Consecuencias de la flexibilidad. 5. Conclusiones.

Cómo citar: Fernández de Casadevante Mayordomo, M. (2020) La Ley de Enjuiciamiento Criminal y la Ley 4/2015 del Estatuto de la Víctima de delito: sus lagunas y consecuencias en el ámbito de la traducción y la interpretación, en Estudios de Traducción 10, 203-212.

Universidad Rey Juan Carlos

maria.fernandezdecasadevante@urjc.es 


\section{Introducción}

Que el fenómeno migratorio se ha visto intensificado en los últimos tiempos es un hecho; durante su recorrido y una vez alcanzado el destino en cuestión, estos inmigrantes se enfrentan a numerosas dificultades. Estas circunstancias les llevan a tener que enfrentarse al temor, al desconcierto o la confusión, más aún si se encuentran en situación irregular. Necesitan que se les respete, proteja, se les trate adecuadamente, se les proporcione información clara y se haga justicia.

Desde el punto de vista lingüístico, la Traducción e Interpretación (TeI) en los servicios públicos en general se ha convertido en una pieza clave para estas personas, a las que se asiste en diferentes ámbitos, como puede ser el ámbito judicial, y sin cuya existencia su día a día y posible integración estaría lleno de obstáculos.

A este respecto, si tenemos en cuenta que la legislación reconoce el derecho a un acceso igualitario a la justicia y a un proceso con todas las garantías, se puede afirmar que este no se verá garantizado sin un servicio de traducción de calidad, o lo que es lo mismo, el llevado a cabo por traductores ad hoc. Desde un punto de vista exigente, para ofrecer un proceso con todas las garantías, todo lo que dice cada una de las personas que intervienen en el proceso penal debería ser traducido desde que el sujeto en cuestión es detenido; Vidal (2007: 214) incide en que esta es una postura maximalista e irreal.

Ortega Herráez (2006: 91), uno de los autores actuales que más ha escrito acerca de la interpretación judicial, nos recuerda que el objetivo principal de este tipo de interpretación es "garantizar la igualdad de condiciones en sus relaciones con la justicia de toda persona que no comparta el idioma del tribunal".

Queremos centrarnos en dos leyes que, si bien recogen el derecho a la TeI, presentan ciertas lagunas y convierten a sus protagonistas en víctimas al estar desprovistos de una TeI de calidad, ya que a menudo esta la llevan a cabo personas sin cualificación, sin la formación y la preparación necesarias, lo que provoca que la población migrante más desfavorecida y sin recursos carezca por lo tanto de dicha igualdad de condiciones. No obstante, adelantamos que, como Jimeno (2007b: 4) apunta, al menos en estos casos, el legislador prima el derecho de defensa, dando prioridad al derecho a intérprete, relegando a un segundo plano el que dicho intérprete esté o no capacitado profesionalmente.

De este modo, nos referiremos a la Ley de Enjuiciamiento Criminal (LECrim), de 1882 para ver que constituye, como afirma Valero Garcés (2006: 31), una ley ambigua, y a la Ley 4/2015 del Estatuto de la Víctima de delito, que podría quedarse en una mera declaración de intenciones si no se garantiza la dotación de medios materiales necesarios (Daza 2014), algo que podría suceder si tenemos en cuenta la ausencia de dotación presupuestaria para este fin, para como colofón presentar algunas de las consecuencias fruto de recurrir a soluciones ad hoc.

Pretendemos así concienciar al lector sobre la necesidad de que estas y otras normas recojan una serie de requisitos y obligaciones relacionadas con la TeI, de cara a ofrecer un servicio que, a su vez, garantice, entre otros, la tutela judicial efectiva.

\section{Ley de Enjuiciamiento Criminal}

Por un lado queremos referirnos a la Ley de Enjuiciamiento Criminal (LECrim), de 1882, que dedica varios artículos al derecho del acusado a la TeI. Destacamos su artículo 441, que establece cómo debe nombrarse el intérprete y qué titulación debe 
tener: en primer lugar, será nombrado de entre los que tienen el título de tales, si los hubiere en el pueblo. De lo contrario, se nombrará a un maestro del correspondiente idioma, y si tampoco lo hubiese, a cualquiera que sepa la lengua.

A este respecto, si bien la teoría es que parece quedar establecido un orden de prelación a la hora de elegir quién llevará a cabo la interpretación, según señala Del Pozo (2013: 120) la práctica es bien diferente, y es que si tenemos en cuenta el sistema que los juzgados y tribunales españoles tienen para proveer los servicios de TeI, ni mucho menos se sigue este orden de prelación, sino que se contrata literalmente a cualquiera que diga saber la lengua, con sus debidas consecuencias.

Pero en abril de 2015, y con el fin de transponer la Directiva 2010/64/UE, de 20 de octubre de 2010, relativa al derecho a interpretación y a traducción en los procesos penales y la Directiva 2012/13/UE, de 22 de mayo de 2012, relativa al derecho a la información en los procesos penales, se publica la Ley Orgánica 5/2015, de 27 de abril, y se modifica, entre otras, la LECrim.

Aunque ya menciona la posibilidad de contar con un intérprete o una traducción, no cuenta con ningún capítulo específico; así, se introduce un nuevo capítulo II al Título V, que incluye los artículos 123 a 127, y que hace referencia al derecho a la TeI en los juicios criminales. Destacamos el artículo $124^{2}$, que establece que el traductor o intérprete judicial será designado de entre aquellos que se hallen incluidos en los listados elaborados por la Administración competente, pudiéndose habilitar como intérprete o traductor judicial eventual, excepcionalmente, a otra persona conocedora del idioma empleado que se estime capacitada para el desempeño de dicha tarea.

Además establece la posibilidad, por parte del Juez, Tribunal o Ministerio Fiscal, de ordenar la realización de las comprobaciones necesarias y, en su caso, ordenar la designación de un nuevo traductor o intérprete si la traducción o interpretación no ofreciese garantías suficientes de exactitud. No obstante, no dice nada de aspectos tan importantes como el modo de controlar y acreditar esas circunstancias o el momento procesal oportuno y los plazos para impugnar esa ausencia de calidad.

La transposición de la Directiva 2010/64/UE no parece haberse llevado a cabo con demasiado acierto, parafraseando a Gascón (2017: 26), y entre otros aspectos, porque mientras esta señala que debe existir un mecanismo para la comprobación de la necesidad de intérprete, la LECrim ha asignado en el artículo 125 dicha función al juez, que recordemos es jurista, no lingüista.

Asimismo, llama la atención que nada se haya modificado con respecto al artículo 441 de la nueva LECrim, donde las palabras utilizadas suenan anticuadas y donde se permite que un maestro o cualquier persona que sepa el idioma pueda llevar a cabo la interpretación ${ }^{3}$. Y por si esto no fuera suficiente, el artículo 762.8 de la LECrim, relativo al procedimiento abreviado, elimina cualquier tipo de requisito al afirmar que "cuando los imputados o testigos no hablaren o no entendieren el idioma español, se procederá de conformidad con lo dispuesto en los artículos 398, 440 y 441, sin que sea preciso que el intérprete designado tenga título oficial".

2 BOE: Ley Orgánica 5/2015, por la que se modifican la Ley de Enjuiciamiento Criminal y la Ley Orgánica 6/1985, de 1 de julio, del Poder Judicial, para transponer la Directiva 2010/64/UE, de 20 de octubre de 2010, relativa al derecho a interpretación y a traducción en los procesos penales y la Directiva 2012/13/UE, de 22 de mayo de 2012, relativa al derecho a la información en los procesos penales. Madrid. 28 de abril de 2015.

3 "El intérprete será elegido entre los que tengan títulos de tales, si los hubiere en el pueblo. En su defecto, será nombrado un maestro del correspondiente idioma, y si tampoco le hubiere, cualquier persona que lo sepa". 
Como apunta Jimeno (2007a: 166), si bien es sorprendente que se afirme algo así existiendo toda una regulación normativa relativa al acceso a la profesión de intérprete jurado y a pesar de que la Oficina de Interpretación de Lenguas del Ministerio de Asuntos Exteriores y de Cooperación se encarga del nombramiento de estos profesionales, hay que tener en cuenta que el legislador ha antepuesto en estos artículos el derecho de defensa y así el derecho a intérprete al de la capacitación profesional.

Pero, en lo que a nosotros atañe, parece que se está intentando aplicar en la actualidad una norma de 1882 y, en palabras de Valero Garcés (2006: 31), la ambigüedad de esta ley hace que lo que al principio se admitía como excepción haya pasado a ser la norma. ¿Acaso nos encontramos ante un trabajo que cualquiera que domine la lengua puede desempeñar? ¿Qué garantías va a tener el imputado de que lo quiere decir y debe entender se transmite conforme a lo que debería hacer un intérprete jurado?

Además, si el intérprete proporciona una interpretación con errores, es probable que no conozca las consecuencias legales que esto tiene. En base a lo anterior podemos apoyar las palabras pronunciadas por Zulueta San Sebastián, quien sostiene que el papel del traductor-intérprete está muy poco valorado, teniendo en cuenta que una buena traducción o interpretación, es decir, la que llevan a cabo profesionales cualificados, establece una buena relación de confianza, mientras que una mala, esto es, la realizada por personas sin la formación necesaria, puede suponer una posible pérdida de libertad, además de suponer una minusvaloración del derecho a la defensa y genera una situación de injusticia estructural (Zulueta 2014). Es por ello que consideramos que la utilización de un intérprete sin formación debería reservarse, en todo caso y de forma excepcional, para cuando no exista intérprete o traductor con titulación oficial, como puede suceder con las lenguas minoritarias.

Esta Ley encierra otro problema, y es que ha transpuesto la Directiva 2010/64/UE con retraso; los Estados miembros, incluido España, disponían de tres años para incorporar la medida a su Derecho nacional, plazo que venció el 27 de octubre de 2013.

\section{Ley 4/2015 del Estatuto de la Víctima de Delito}

Por otro lado, nos encontramos con la Ley 4/2015 del Estatuto de la Víctima de delito. El objetivo de la misma, cuya publicación en el BOE núm. 101 se produce el 28 de abril de 2015 y que está vigente desde octubre de ese mismo año, es

ofrecer desde los poderes públicos una respuesta lo más amplia posible, no sólo jurídica sino también social, a las víctimas, no sólo reparadora del daño en el marco de un proceso penal, sino también minimizadora de otros efectos traumáticos en lo moral que su condición puede generar, todo ello con independencia de su situación procesal ${ }^{4}$.

Asimismo, su creación fue pensada para transponer la normativa europea en esta materia. Todo comienza con la Decisión Marco 2001/220/JAI del Consejo, de 15 de marzo de 2001, relativa al estatuto de la víctima en el proceso penal, que en 2009 es objeto de informe por parte de la Unión Europea. En ella se concluye que no hay ningún Estado miembro que haya unificado toda la ley en materia de derechos de la víctima, y establece

4 BOE: Ley 4/2015, del Estatuto de la Víctima, Preámbulo I. Madrid. 28 de abril de 2015. 
que España sí cuenta con un marco normativo que garantice estos derechos, aunque la mayoría son derechos procesales o se centran en un tipo de víctima muy concreto.

En este contexto se aprueba la Directiva 2012/29/UE del Parlamento Europeo y del Consejo, de 25 de octubre de 2012, que recoge normas mínimas sobre los derechos, el apoyo y la protección de las víctimas de delitos, y sustituye a la Decisión Marco 2001/220/JAI del Consejo; asimismo, establece un plazo para proceder a su incorporación al derecho interno: el 16 de noviembre de 2015.

El derecho de las víctimas de delito que desconocen el idioma en el que se desarrolla el juicio a ser asistidos por un intérprete está reconocido por vez primera y explícitamente en Europa en el artículo 7 de la Directiva 2012/29/UE, donde se recoge el derecho a TeI para garantizar así los derechos a que la víctima reciba información (arts. 4 y 5) y entienda y sea entendida (artículo 3), como nos recuerda Antón (2014: 11).

España optó por redactar el Estatuto de la Víctima y transponer tanto esta Directiva 2012/29/UE como la Directiva 2011/93/UE del Parlamento Europeo, relativa a la lucha contra los abusos sexuales y la explotación sexual de los menores y la pornografía infantil, así como la Directiva 2011/36/UE del Parlamento Europeo y del Consejo, de 5 abril de 2011, relativa a la prevención y lucha contra la trata de seres humanos y a la protección de las víctimas, por la que se sustituye la Decisión marco 2002/629/JAI del Consejo.

En cuanto a la TeI, que es el tema que nos concierne, uno de los derechos básicos que se recoge en el Estatuto de la Víctima es el de la víctima a entender y ser entendida (artículo 4). Si bien no se hace mención específica a la traducción o la interpretación, el hecho de establecer que las comunicaciones con las víctimas deberán hacerse "en un lenguaje claro, sencillo y accesible, de un modo que tenga en cuenta sus características personales" nos lleva a concluir que en el caso de una víctima que no conozca la lengua en cuestión será necesario proporcionarle un traductor-intérprete, sin cuya asistencia la víctima difícilmente podrá entender o ser entendida. Por otra parte, el artículo 6 recoge el derecho de la víctima como denunciante a obtener asistencia lingüística gratuita a la víctima que desee interponer denuncia y traducción gratuita de la copia de la denuncia presentada ${ }^{5}$.

Por otro lado, el artículo 9 establece que recibirá asistencia gratuita por parte de un intérprete en la fase de investigación por el juez, el fiscal o funcionarios de policía, cuando intervenga como testigo en el juicio y en cualquier otra vista oral.

Sin embargo, si analizamos la Disposición adicional segunda, referente a los medios, se trata de una ley llena de buenos propósitos sin que en realidad vayan a incrementarse las dotaciones de personal, ni de retribuciones ni de otros gastos de personal. Por lo tanto, si no se prevé más dotación presupuestaria para llevar a cabo todo lo que se proponen hacer es difícil que se puedan contratar más servicios. Como consecuencia de lo anterior, ¿cómo es el servicio que se ofrece en nuestro país?

La flexibilidad de la legislación ha permitido que cada juez habilitase como intérprete a cualquiera, y que fuesen los funcionarios judiciales los encargados de localizar un profesional de la TeI, lo cual ha sido aprovechado por intérpretes que se han dirigido a los juzgados repartiendo su tarjeta de visita y ofreciendo así directamente sus servicios (Ortega 2010: 96-97); en ocasiones, los juzgados han contactado con empresas especializadas que les proporcionan los traductores-intérpretes.

5 BOE: Ley 4/2015, del Estatuto de la víctima del delito. Madrid, 28 de abril de 2015. 
La ley permite actuar como intérprete sin necesidad de contar con un título; no existe un examen de acceso a la profesión ni se comprueba la competencia lingüística ni jurídica (Ortega 2010: 105-107).

\section{Consecuencias de la flexibilidad}

Esto ha hecho que, por ejemplo, como señala Bourgoin (2016: 66), en la Justicia se tienda a la licitación del servicio y la posterior contratación de personal no cualificado, además de recurrir a soluciones $a d$ hoc, o lo que es lo mismo, a la utilización de familiares o personas cercanas para mediar lingüísticamente en el proceso judicial, lo que, según sus palabras, ha causado anulaciones o aplazamientos entre algunos incidentes procesales.

Entre otros se ha recurrido a población china, la mayoría trabajadores de restaurantes, que aunque son personas bilingües carecen de formación en TeI (Nieto 2005: 197); en otras ocasiones se firman en las comisarías de policía contratos de TeI con ONG que, a cambio de realizar este servicio, reciben una subvención. Muchos de ellos, aparte de por supuesto no conocer bien la lengua de destino, no dominan su propia lengua materna; carecen de preparación, no conocen los procedimientos administrativos de nuestro país ni siguen ningún código ético (Benhaddou 2005: 265-266). Asimismo, se ha hecho uso de profesores del cuerpo de Escuelas Oficiales de Idiomas, o de personas que simplemente afirman hablar la lengua que se necesita (Ritap 2011). Incluso sucede que acceden al puesto sin que se les realice ninguna prueba.

Como señala Benhaddou (2005: 265-266), un traductor sin formación ni experiencia pregunta y responde sin tener en cuenta ni al agente ni al sospechoso, omite o resume información, y elabora el discurso de su cliente. Así, por ejemplo, tras analizar diferentes vistas interpretadas en inglés, rumano y francés, el grupo de investigación MIRAS concluía que solamente se traduce y se refleja en acta un $30 \%$ (lo que queda grabado) de cada juicio; a esto hay que añadir un $16 \%$, correspondiente a la información que el intérprete susurra al acusado al oído y que, por lo tanto, no queda grabado (Universidad Autònoma de Barcelona 2017). Como consecuencia, se puede decir que, de media, no se interpreta más de la mitad de un juicio (el $54 \%$ de la información hablada) - $51 \%$ en inglés, $39 \%$ en francés y $61 \%$ en rumano-, porcentajes que comprenden tanto la interpretación en voz alta, que queda registrada en las grabaciones, como la que hace el intérprete al acusado al oído y que, por lo tanto, no queda grabada.

En cuanto al número medio de intervenciones enteras por minuto que no se traducen, este es de 2,7 (1,8 en inglés, 1,6 en francés y 3,7 en rumano, dato este último que resulta alarmante para las autoras del estudio llevado a cabo por la Universidad Autónoma de Barcelona), lo que demuestra que el derecho del acusado a saber lo que está sucediendo en su propio juicio se vulnera sistemáticamente.

Tengamos en cuenta que, ya de por sí, en un juicio se producen solapamientos verbales frecuentes entre los operadores judiciales, y que la velocidad de habla es muy alta (de hasta 240 palabras por minuto), aspectos que dificultan una interpretación precisa y completa. ¿Qué imprecisiones va a haber si el intérprete no está cualificado? El inmigrante se encontrará en una posición de indefensión y desigualdad frente a quienes hablan español, violando sus derechos y haciendo que, además de la víctima, el acusado se convierta en otra víctima. 
Como ejemplo, un juicio en el que al acusado por delito contra la salud pública se le comunica de forma errónea el importe de la pena de multa (180 € en lugar de $180000 €$ ), a lo que él da su conformidad a pesar de que no le ha sido transmitido correctamente; es decir, acepta una sentencia que es firme, de extrema gravedad por lo que ello implica (Bestué 2018: 151).

El hecho de que quien lleva a cabo la TeI no sea un profesional cualificado puede conducir a una interpretación con errores, lo que según diversos autores puede suponer la pérdida de libertad (De Luna 2010), si por ejemplo, "se confunde la palabra acariciar con tocamientos, o puñetazo con puñalada, o cuchillo con machete".

Asimismo, el hecho de contratar personal no profesional que no se adhiere a un código ético puede dar lugar a problemas como el que se daba en 2006, cuando la Brigada de Extranjería del Cuerpo Nacional de Policía en Tenerife contrataba a dos senegaleses como intérpretes de las lenguas wolof y bambara en los interrogatorios a los inmigrantes que llegaban a la isla en cayucos. Desde entonces, y hasta ser detenidos, ambos individuos, con residencia en España, estuvieron manipulando las respuestas de miles de ilegales a cambio de dinero.

Así, cuando la Policía preguntaba al inmigrante el país de origen, el intérprete decía: "Te pregunta de qué país eres. Si dices que eres de Senegal, te repatriarán. Pero si me pagas, yo diré que eres de Costa de Marfil y no podrán deportarte". Normalmente el inmigrante ilegal aceptaba el trato, tras lo cual el intérprete diría al agente que era de Costa de Marfil para así cumplir con el pacto y evitar la deportación. Además, tenían acceso a información reservada, la cual utilizaban para alertar a mafias de Senegal y de Mali del momento en que las lanchas debían zarpar y de las rutas que debían seguir (El País 2007).

En 2008, Seprotec, y a petición de la Policía, envía a un TeI al aeropuerto de Barajas para explicar a una pareja de Brasil que sus papeles no están en regla: la primera sorpresa para la Policía al llegar el intérprete, que debe traducir al portugués, es ver que se trata de un ciudadano pakistaní. Pero lo que es más grave, tiene seis antecedentes policiales, entre los que destacan dos delitos por falsificación de documentos y otro más por tráfico de drogas, así como una orden de búsqueda y captura; ante esto, es detenido. Un tiempo después vuelve a suceder lo mismo con un ciudadano kurdo también con antecedentes (20 Minutos 2008).

\section{Conclusiones}

Los datos aportados permiten concluir que contar con un intérprete no garantiza un juicio justo. A este respecto, la Directiva 2010/64/UE suponía un avance en la búsqueda por mejorar la calidad de la interpretación judicial al exigir de forma expresa una TeI de calidad suficiente y establecer un registro oficial de traductores e intérpretes judiciales independientes debidamente cualificados. No obstante, su transposición mediante la aprobación de la LO 5/2015, que modifica, entre otras, la LECrim, encierra algunos aspectos negativos y ha permitido, como hemos visto anteriormente, que cualquiera que maneje las lenguas lleve a cabo la interpretación.

Preocupa con relación a este tema la posibilidad de que al registro puedan acceder personas jurídicas, lo que haría que nos encontrásemos en la misma situación de inseguridad que antes de la aplicación de la Directiva. No obstante, el proyecto de ley de creación del Registro para trasladar a nuestra legislación lo dispuesto en la 
Directiva 2010/64/UE en el primer cuatrimestre de 2020 aún no se ha presentado, más de seis años después de que venciera el plazo, el 27 de octubre de 2013.

De cara a su creación surgen varias posibilidades: sería positivo crear en nuestro país un registro, el cual no se convierta en una lista de empresas que contratan a intérpretes sin acreditación sino al que solamente accedan personas físicas y cualificadas que hayan tenido que pasar por un estricto proceso de selección y acreditación, que se hayan enfrentado a unas pruebas objetivas, válidas y fiables, además de contar con un código deontológico común por el que regirse y tener la obligación de actualizarse periódicamente mediante la realización de cursos de formación.

Por otro lado, y aunque esta Directiva se refiere únicamente a la jurisdicción penal, bien podría hacerse lo que sugieren Gámez y Cuñado: exigir la creación de un registro que sirviera de referencia para proveer a toda la Administración de Justicia pues, apuntan, a nuestro país le tiene que resultar especialmente sencillo si tenemos en cuenta que ya existe un registro oficial de traductores e intérpretes jurados gestionado por el Ministerio de Asuntos Exteriores (Cuñado 2012: 30-32).

Además, ante la existencia de un Registro es fundamental que exista la figura de un coordinador interno, sin intermediarios. Es por ello que consideramos positivo apoyarnos en el caso canario, donde un coordinador de intérpretes externos ofrece un servicio con garantías si tenemos en cuenta que su labor evita la precarización laboral de intérpretes, su desprofesionalización y desprestigio ${ }^{6}$.

Si bien ningún sistema garantiza realmente una vigilancia eficaz de la calidad, la gestión interna directa por parte de profesionales en TeI es la única forma viable y disponible que puede ejercer un control directo de los servicios y certificar que, en cada momento, el servicio lo preste el mejor profesional disponible.

\section{Referencias}

20 minutos, "Una empresa envía a la Policía Nacional traductores con antecedentes" (30 de mayo de 2008). Disponible en http://www.20minutos.es/noticia/384035/0/ antecedentes/traductores/policia/.

Antón García, L., "Barrera idiomática y derecho a la información de las víctimas de violencia de género. El servicio de interpretación en el sistema penal de Cataluña", Indret Criminología 2 (2014), 1-33. Disponible en: https://indret.com/ wp-content/themes/indret/pdf/1040.pdf.

Benhaddou Handi, E., "Las funciones de los traductores en las investigaciones policiales", en: Valero Garcés, C. (ed.), Traducción como Mediación entre Lenguas y Culturas. Alcalá de Henares: Universidad de Alcalá 2005, 265-271.

Bestué, C., "Aproximación empírica a la labor del intérprete en los tribunales de justicia", en: Ariza Colmenarejo, M. J. (ed.), Traducción, interpretación e información para la tutela judicial efectiva en el proceso penal. Valencia: Tirant Lo Blanch 2018, 139-158.

Bourgoin Vergondy, E. C., "Odisea en el espacio público de la TeI", en: Ferreiro Vázquez, Ó. (ed.), Traducir para lo público. Granada: Comares 2016, 63-78.

6 Para más información al respecto, RITAP: Libro blanco de la traducción y la interpretación institucional: conocer para reconocer. Madrid: Ministerio de Asuntos Exteriores y de Cooperación 2011, 90-98. Disponible en: http:/www. ritap.es/wp-content/uploads/2012/11/libro_blanco_traduccion_vfinal_es.pdf (última consulta 12 de febrero, 2019). 
Cuñado de Castro, F., "La validez de los documentos traducidos ante los tribunales de justicia", Revista Abogacía Española 74 (2012). Disponible en: https://www. yumpu.com/es/document/read/43148019/la-validez-de-documentos-traducidosante-los-tribunales-abogaca-a- (última consulta: 16 de septiembre, 2019).

Daza Bonachela, M. M., "Comentario al Proyecto de Ley del Estatuto de la Víctima del Delito", Noticias Jurídicas 2014. Disponible en http://noticias.juridicas.com/conocimiento/articulos-doctrinales/9294-comentario-al-proyecto-de-ley-del-estatutode-la-victima-del-delito/ (última consulta: 8 de septiembre, 2019).

De Luna y Jiménez de Parga, P., "El intérprete judicial: ese interlocutor emocional entre el acusado y el juez", Ponencia para el Congreso Jueces para la Democracia. Bilbao, 2010. Disponible en: http:/www.juecesdemocracia.es/congresos/ xxvcongreso/ponencias/E1\%20interprete\%20Judicial.\%20Pilar\%20Luna.pdf (última consulta: 1 de septiembre, 2019).

Del Pozo Triviño, M., "El camino hacia la profesionalización de los intérpretes en los servicios públicos y asistenciales españoles en el siglo XXI", Cuadernos de Aldeeu 25 (2013), 109-130. Disponible en: https://www.semanticscholar.org/paper/El-camino-hacia-la-profesionalizaci $\% \mathrm{C} 3 \% \mathrm{~B} 3 n$-de-los-en-los-Trevi $\% \mathrm{C} 3 \% \mathrm{~B}$ 1o/1317ed5b1770671e69cb80c263a7ff7e919d0e2e (última consulta: 3 de septiembre, 2019).

El País, "Dos intérpretes de la policía falsearon por dinero las declaraciones de inmigrantes" (1 de agosto de 2007). Disponible en: https://elpais.com/diario/2007/08/01/espana/1185919218_850215.html (última consulta: 5 de septiembre, 2019).

Gascón Nasarre, F., "La Directiva 2010/64/UE: antecedentes de hecho, fundamentos de Derecho y claroscuros de su transposición en España", Punto y Coma 152 (2017), 19-31.

Jimeno Bulnes, M., "El derecho a la interpretación y traducción gratuitas", en: Arangüena Fanego, C. (coord.), Garantías procesales en los procesos penales en la Unión Europea. Valladolid: Lex Nova 2007a, 155-183.

Jimeno Bulnes, M., "Acceso a la interpretación y traducción gratuitas", La Ley 6671 (2007b). Disponible en: https://www.ubu.es/sites/default/files/portal_page/files/ derecho_a_la_interpretacio

a_ley.pdf (última consulta: 11 de septiembre, 2019].

Nieto García, P., "La interpretación social en la policía nacional, guardia civil y policía local de Segovia», en: Valero Garcés, C. (ed.), Traducción como mediación entre culturas. Alcalá de Henares: Universidad de Alcalá 2005, 193-201.

Ortega Herráez, J. M., Análisis de la práctica de la interpretación judicial en España: el intérprete frente a su papel profesional. Tesis doctoral. Universidad de Granada, 2006. Disponible en: http://hdl.handle.net/10481/977 (última consulta: 3 de septiembre, 2019).

Ortega Herráez, J. M., Interpretar para la justicia. Granada: Comares 2010, 96-124. Universitat Autònoma de Barcelona: "Un estudio del grupo MIRAS muestra que más de la mitad de lo que se dice en un juicio con intérprete no se traduce a la persona juzgada. 10 de julio de 2017". Disponible en: http://www.uab.cat/web/ sala-de-prensa/detalle-noticia/un-estudio-del-grupo-miras-muestra-que-mas-dela-mitad-de-lo-que-se-dice-en-un-juicio-con-interprete-no-se-traduce-a-la-persona-juzgada-1345667994339.html?noticiaid $=1345732713413$ (última consulta: 13 de septiembre, 2019). 
Valero Garcés, C., "Las Instituciones oficiales y sus soluciones a los problemas de comunicación", Revista Española de Lingüistica Aplicada Extra 1 (2006), 29-48.

Vidal Fernández, B., "Derecho a una interpretación y traducción fidedigna y de calidad", en: Arangüena Fanego, C. (coord.), Garantías procesales en los procesos penales en la Unión Europea. Valladolid: Lex Nova 2007.

Zulueta San Sebastián, E., Seminario ¿Nuevas perspectivas del Derecho a la Defensa?, Segunda Mesa: La directiva de traducción e interpretación. Segunda mesa del seminario organizado por la Comisión de Defensa de la Defensa el 05 y 06 de junio de 2014 dedicado a analizar las directivas europeas sobre los derechos de las personas sospechosas y acusadas aprobadas en la Hoja de Ruta de Estocolmo de la UE. Disponible en: https://www.youtube.com/watch?v=FRb8WxWc5pQ (última consulta: 13 de septiembre, 2019). 